\title{
Modeling of drug resistance: comparison of two hypotheses on the example of LGGs
}

\author{
Marek Bodnar ${ }^{1}$ and Urszula Forys ${ }^{1}$ \\ ${ }^{1}$ University of Warsaw
}

May 5, 2020

\begin{abstract}
Acquired drug resistance syndrom (ADR) is one of the most important features associated with tumor treatment and it is therefore $\mathrm{a}^{\sim}$ topic of intensive studies. We present two simple mathematical models reflecting different mechanisms of ADR with some Darwinian effects included. These effects allow resistant cells to become sensitive again. Basing on this mathematical approach we conclude that for constant continuous treatment, if no Darwinian effects are present then once resistant cells appear, sensitive cells are eliminated after a long time, independently of the mechanism of acquiring the resistance. However, with Darwinian effects the situation is a little better as the sensitive cells are not completely eliminated but they are still outcompeted by the resistant ones. Moreover, if the therapy is stopped resistant cells become dominated by sensitive cells and the situation changes completely in comparison to the case without Darwinian effects. We discuss these mechanisms on the example of gliomas.
\end{abstract}

\section{Hosted file}

artykul_do_czasopisma_v2019_10_22.pdf available at https://authorea.com/users/296054/ articles/424916-modeling-of-drug-resistance-comparison-of-two-hypotheses-on-the-exampleof-lggs
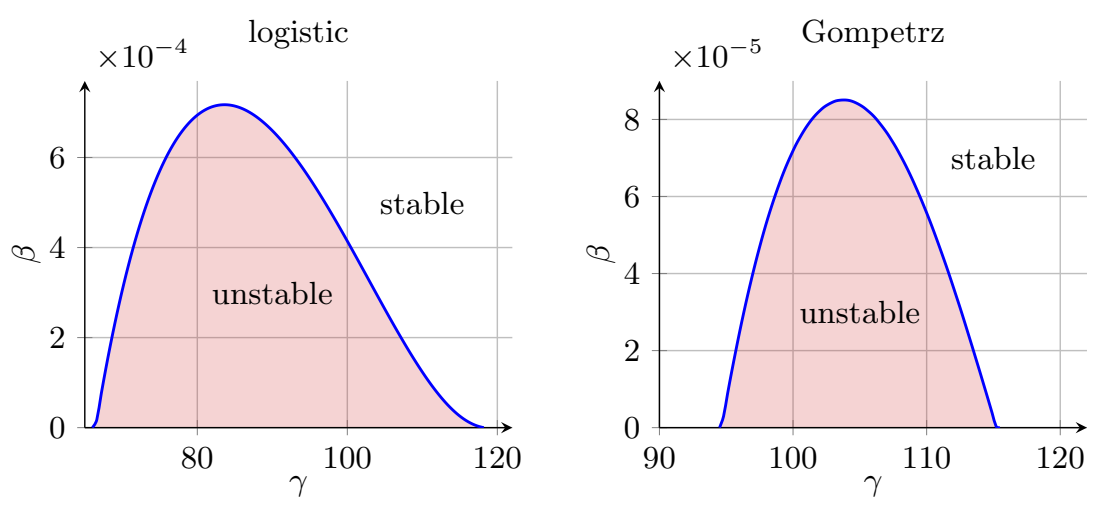

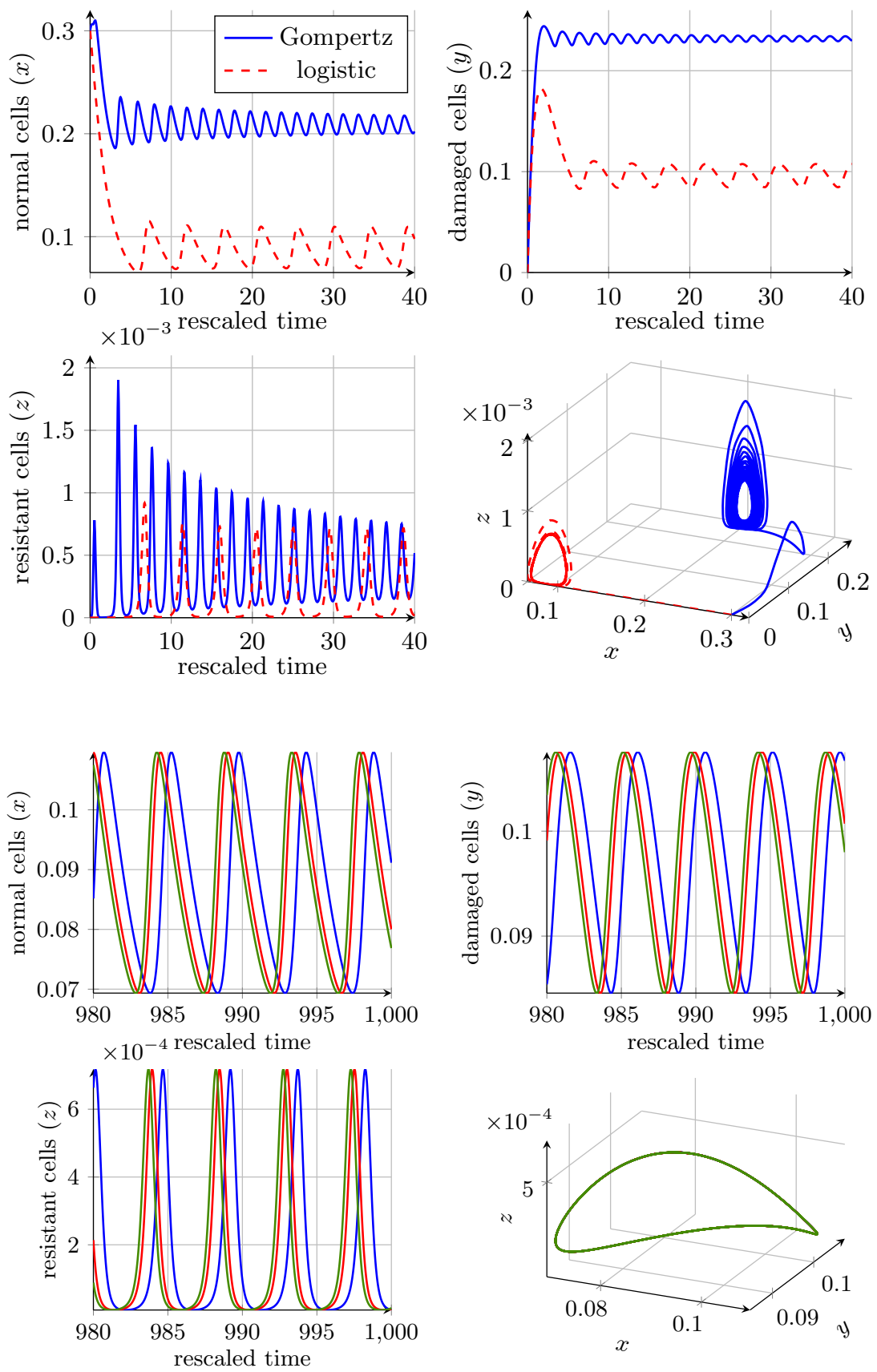

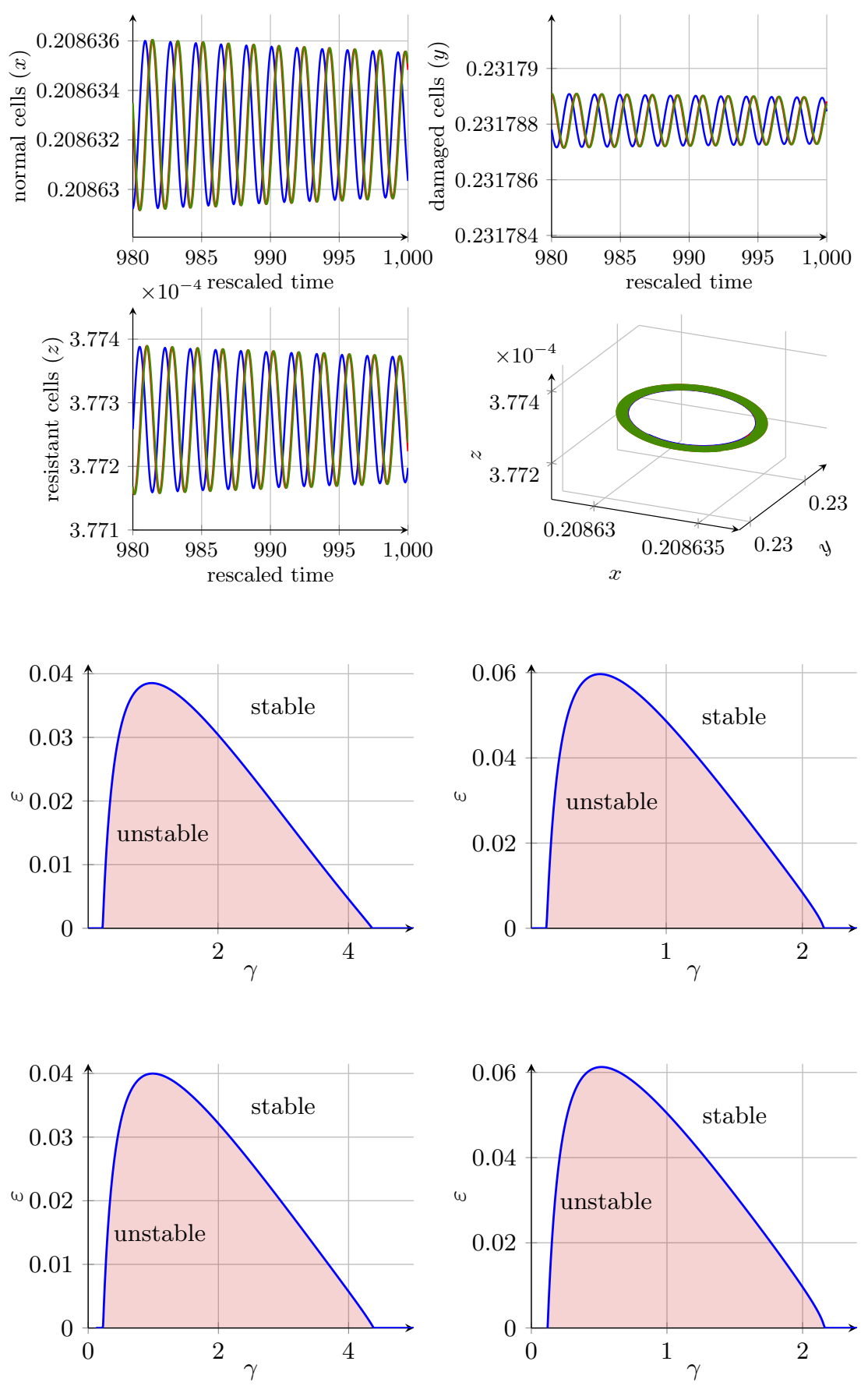

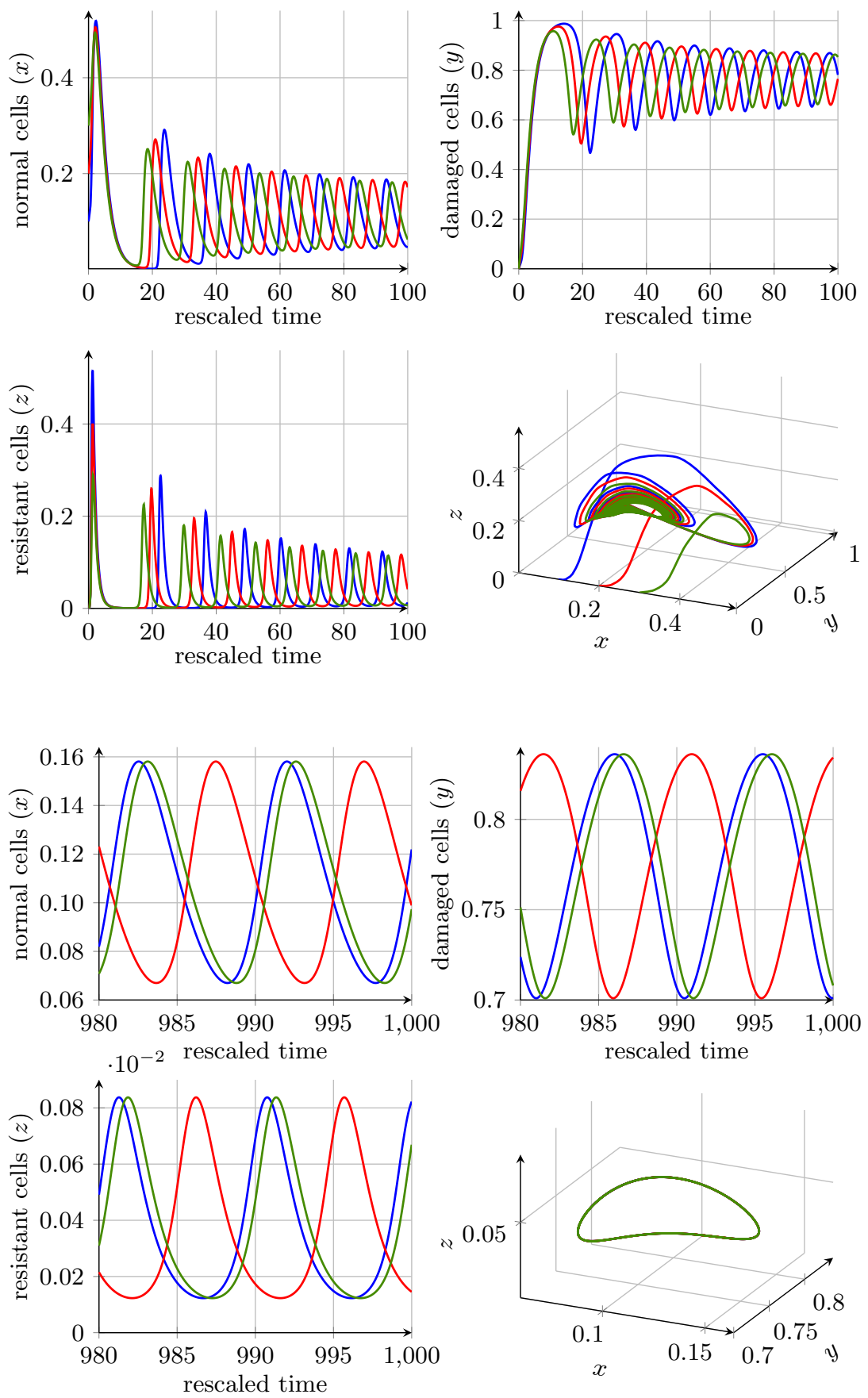

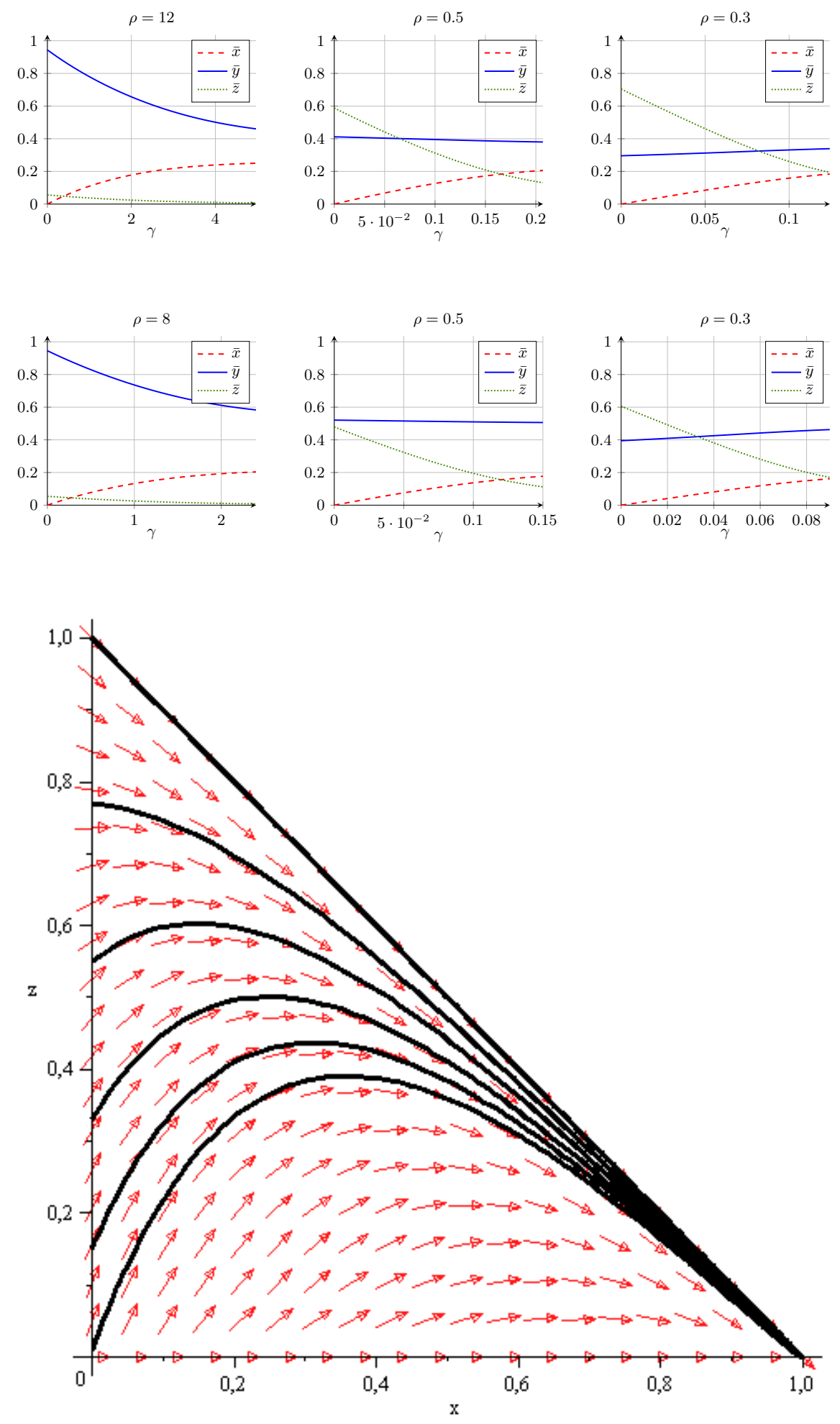


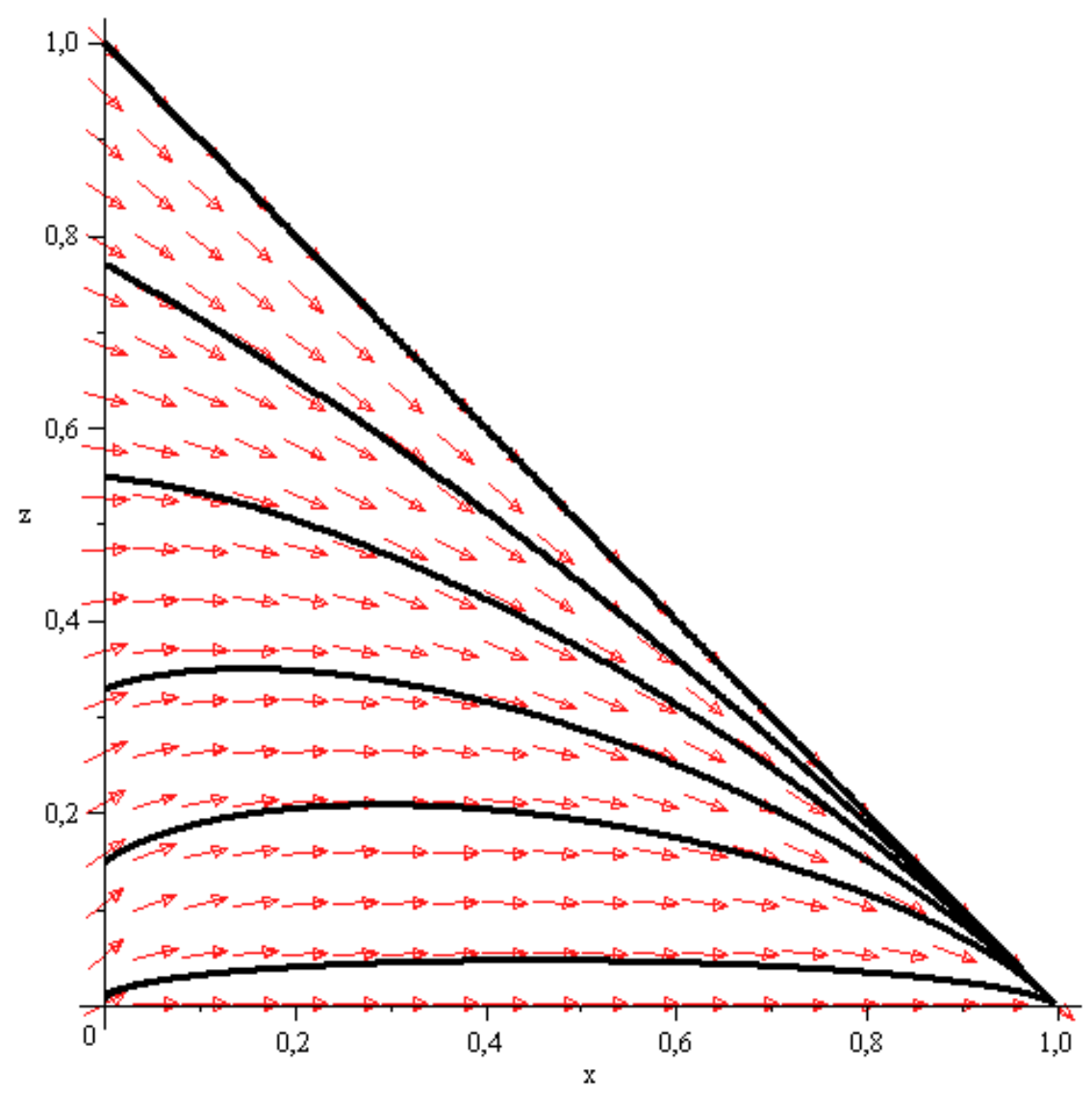




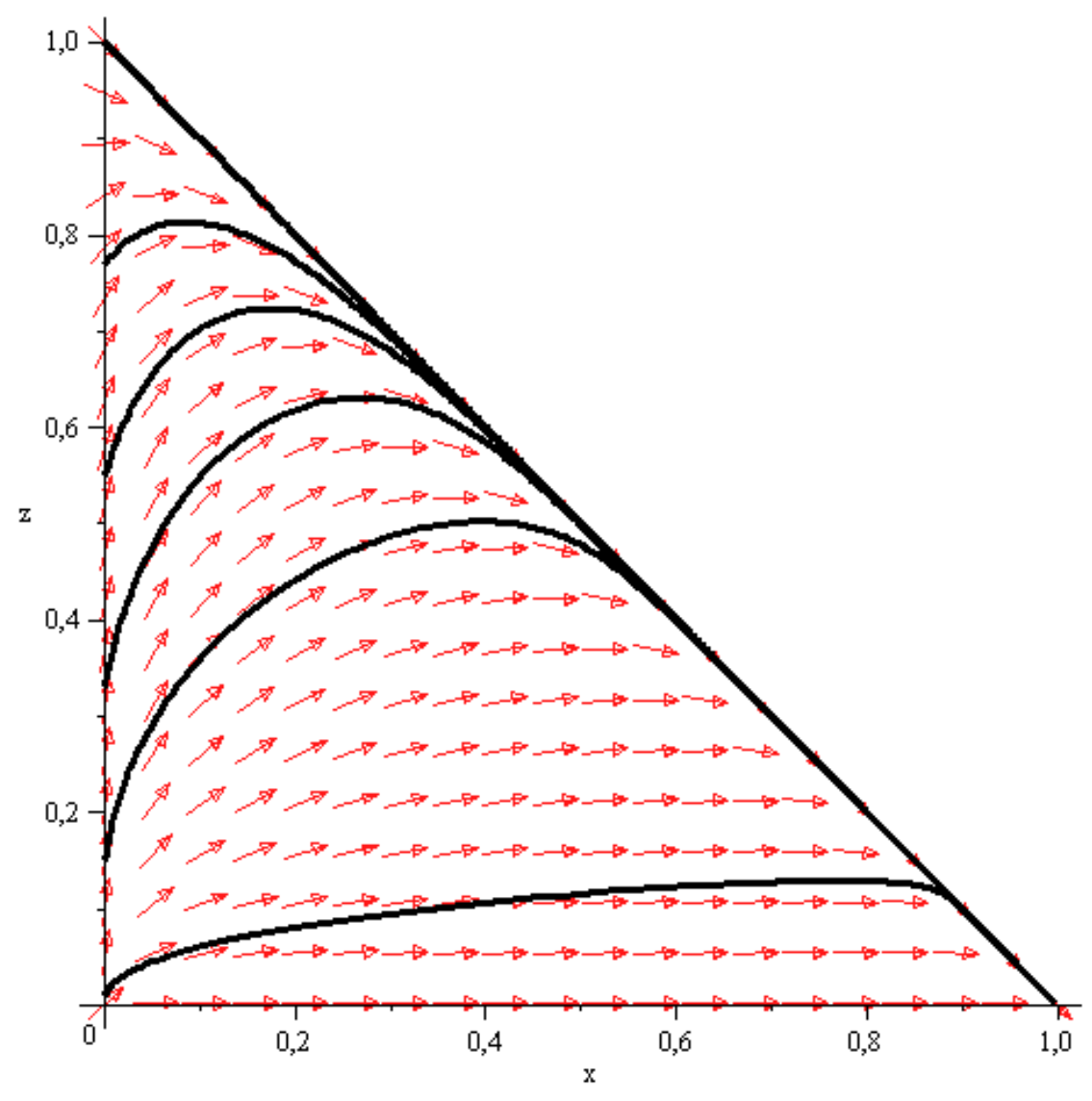




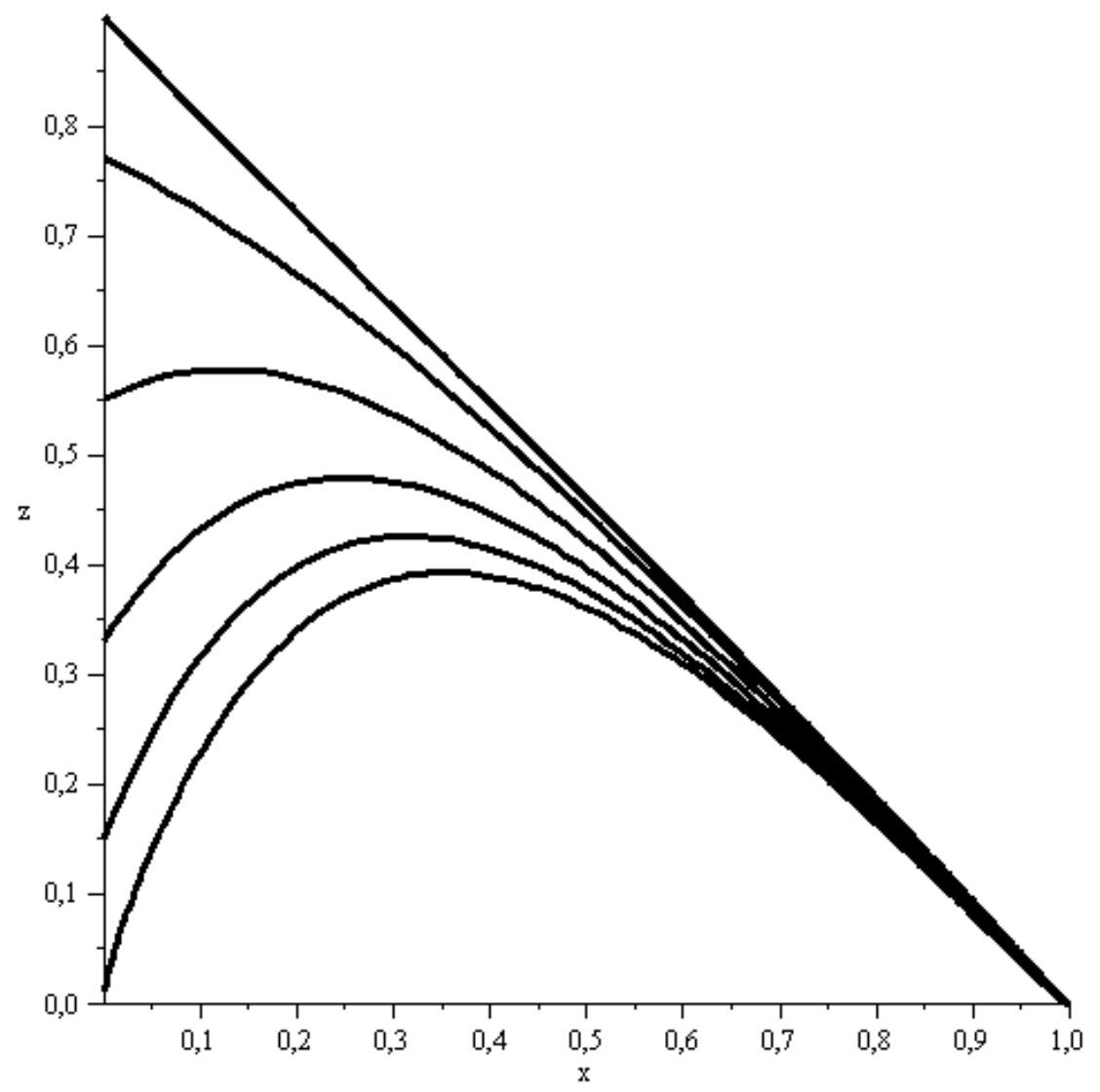




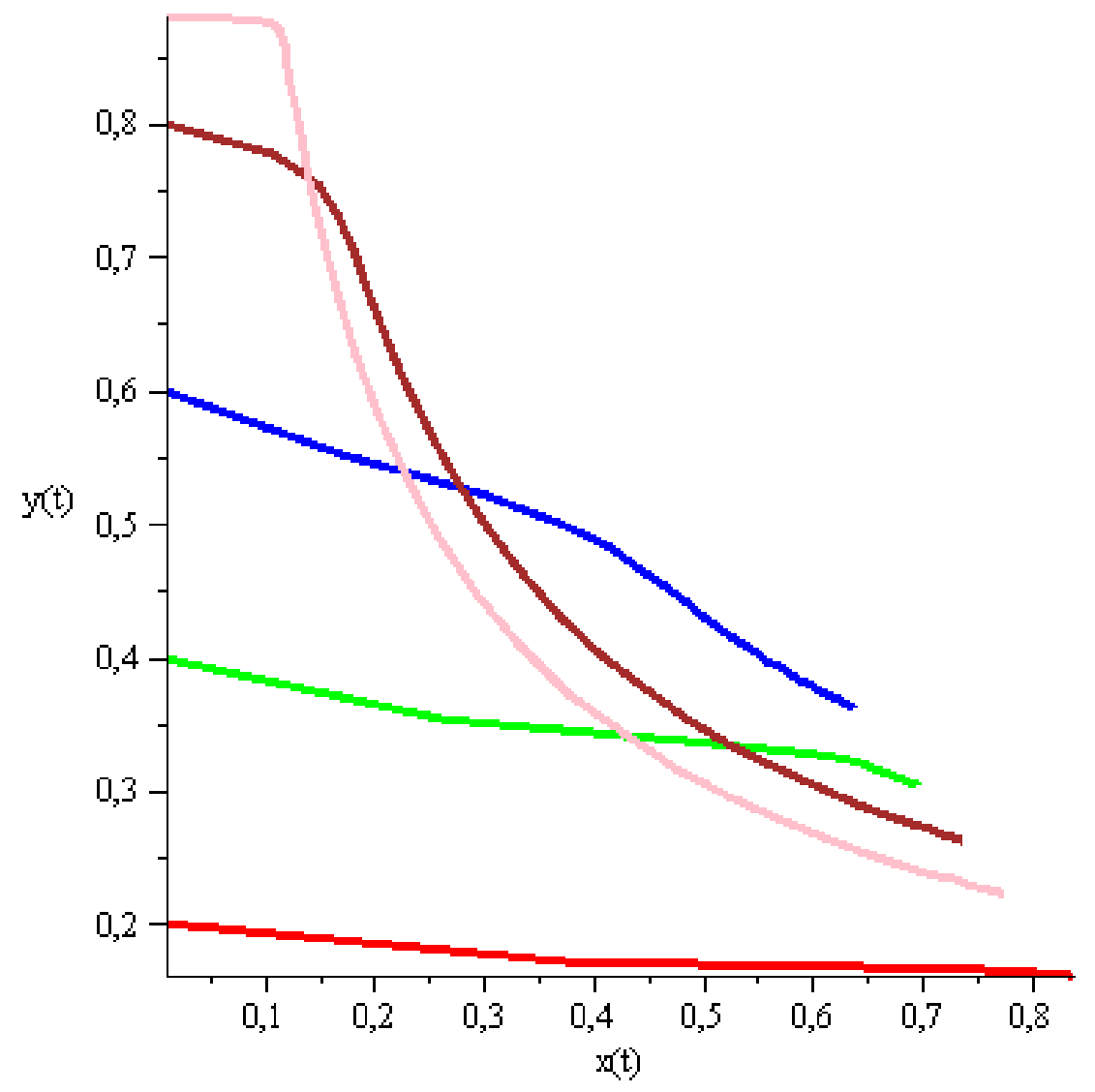




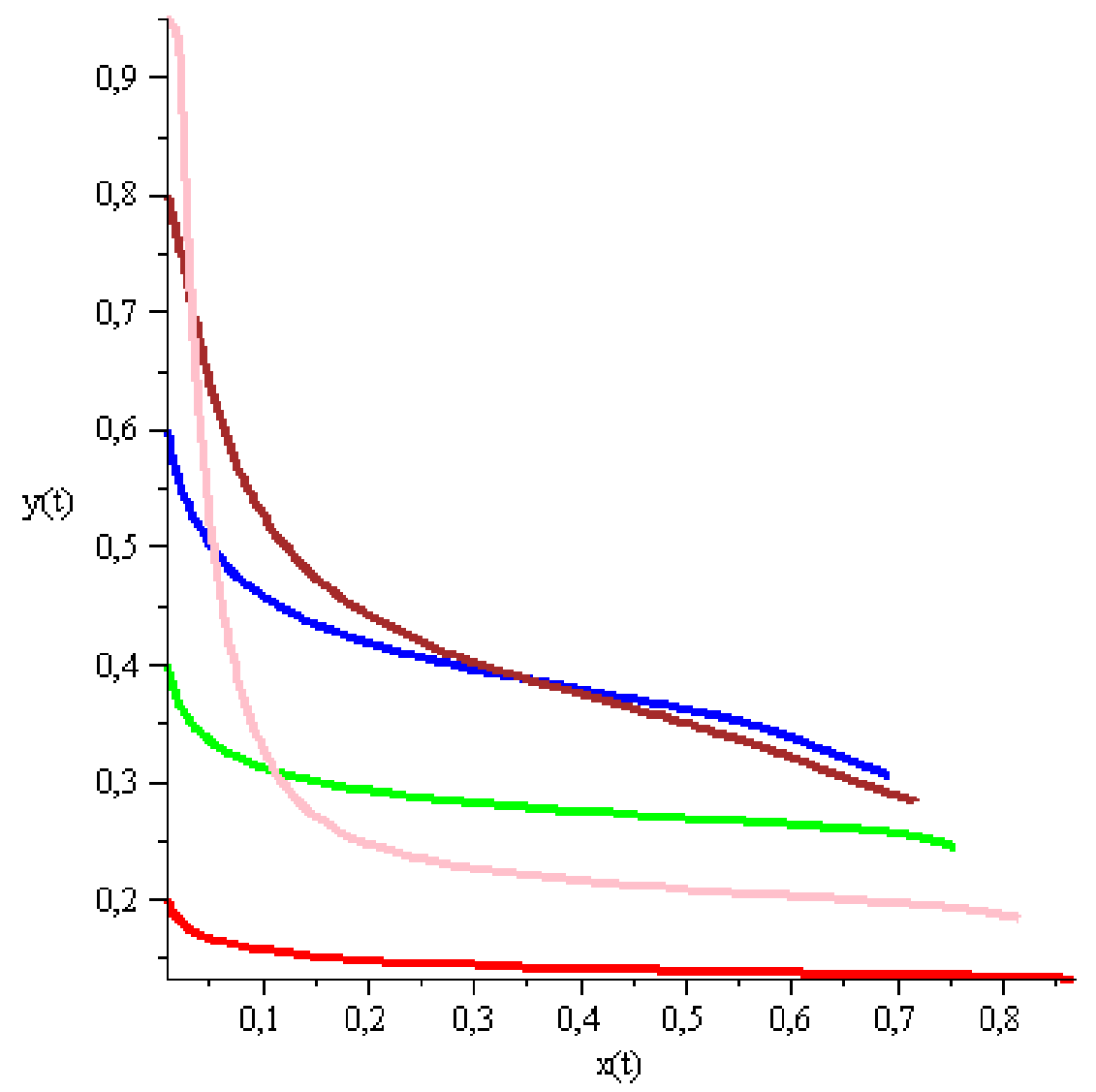




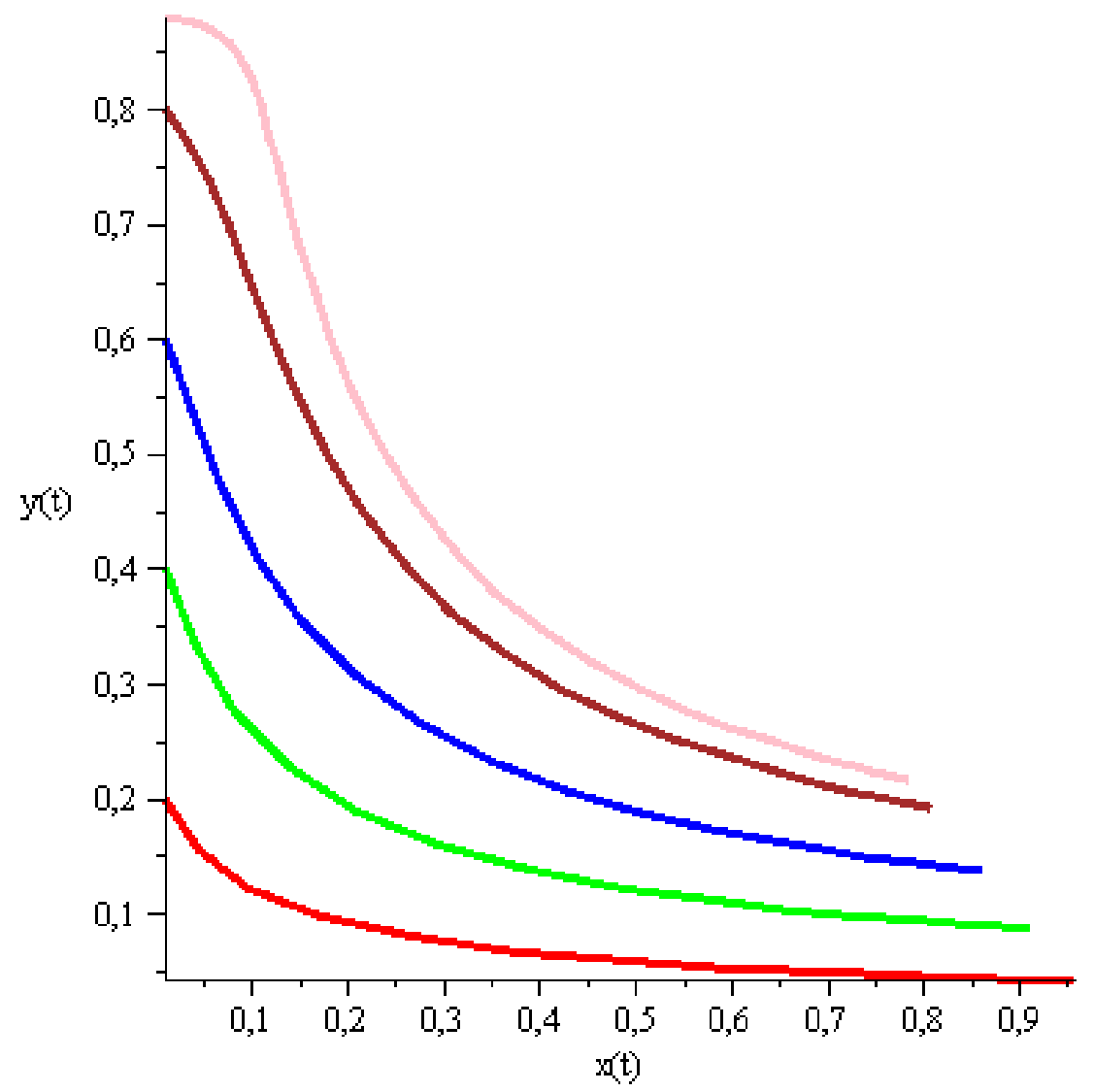




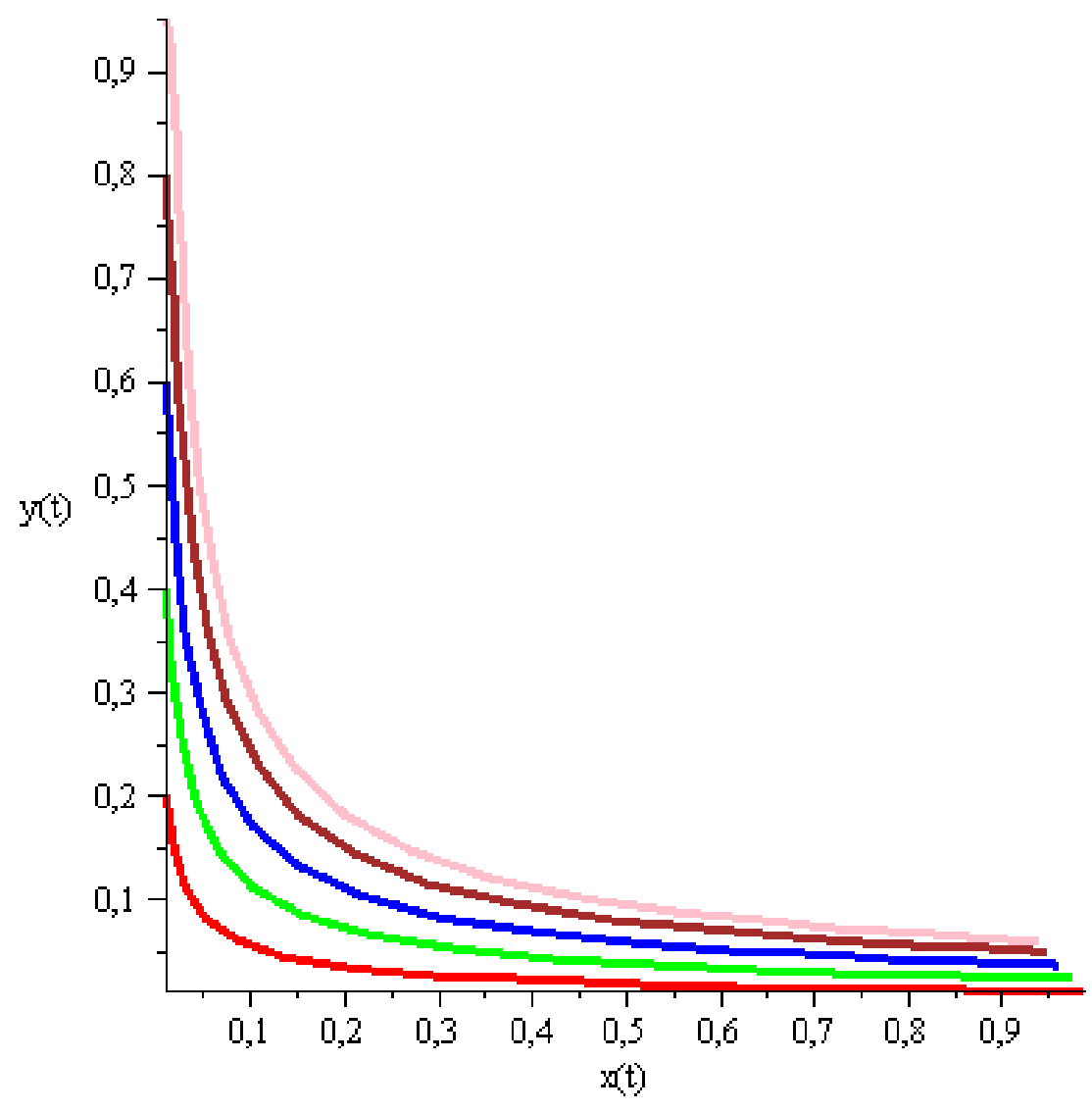

